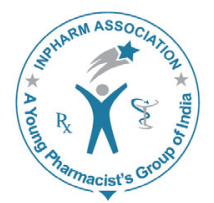

\title{
A Study of Drug Utilization Pattern According to Daily Define Dose in Intensive Care Unit (ICU)s at Tertiary Care Teaching Hospital, India
}

\author{
Prakash Rameshbhai Shelat ${ }^{1}$, Anuradha Mihir Gandhi ${ }^{2}$ and Prakruti Parth \\ Patel $^{2}$
}

${ }^{1}$ Department of Pharmacology, P.D.U. Govt. Medical College, Rajkot, Gujarat, India.

${ }^{2}$ Department of Pharmacology, B.J. Medical College, Ahmedabad, Gujarat, India.

\begin{abstract}
Objective: The goal of study is to identify drug and antimicrobial utilization in ICUs by using daily defined dose. Material and Methods: Study was conducted at tertiary care teaching hospital. 100 patients in each medical, surgical and neurosurgical ICU were included. The data were recorded in preformed Case Record Form (CRF). Drugs were classified using the anatomical therapeutic chemical (ATC) classification system and drug utilization was measured as Daily Defined Dose (DDD)/100 bed days. Data were analyzed by $Z$ and $x^{2}$ test. Results: DDD/100 bed days of inotropes was 51.44 in medical ICU which was significantly $(p<0.05)$ higher compared to surgical and neurosurgical ICU while DDD/100 bed days of gastrointestinal drugs was 44.52, 38.57 and analgesics was $34.5,34.41$ in surgical and neurosurgical ICU respectively which was significantly $(p<0.05)$ higher as compared to medical ICU. More than two antimicrobials were prescribed in above $70 \%$ patients in all ICU. DDD/100 bed days of cephalosporin was 20.76 in medical ICU which was significantly $(p<0.05)$ higher compared to surgical and neurosurgical ICU. DDD/100 bed days of aminoglycosides was 16.01, 17.65 and nitroimidazole was 10.3, 8.4 in surgical and neurosurgical ICU respectively which was significantly $(p<0.05)$ higher compared to medical ICU. Among restricted antimicrobials according to antimicrobial policy of hospital. DDD/100 bed days of piperacillin+tazobactam and cefoperazone+sulbactam were significantly $(p<0.05)$ higher in medical ICU. Levoflxoacin and vancomycin were highly sensitive antimicrobials followed by beta lactam antimicrobials with beta lactamase inhibitors in all ICUs. Conclusion: Polypharmacy was observed in ICU and antimicrobials widely prescribed in ICUs. Sensitivity of beta lactam along with beta lacatamase inhibitors was high.
\end{abstract}

Key words: Antimicrobial agent, Daily Defined Dose, Intensive Care Unit (ICU), Medical, Neurosurgical, Surgical.

\section{INTRODUCTION}

Drug utilization research was defined by WHO as the study of marketing, distribution, prescription, and use of drugs

\begin{tabular}{|c|c|}
\hline \multicolumn{2}{|c|}{ Access this article online } \\
\hline Journal Sponsor & \multirow[b]{2}{*}{$\begin{array}{l}\text { Website: } \\
\text { www.jyoungpharm.org }\end{array}$} \\
\hline \multirow{2}{*}{ www.phcog net } & \\
\hline & $\begin{array}{l}\text { DOI: } \\
\text { 10.5530/jyp.2015.4.9 }\end{array}$ \\
\hline
\end{tabular}

in a society, with special emphasis on the resulting medical, social and economic consequences. ${ }^{1}$ Drug utilization research help in identification of clinical use of drugs in populations and its impact on healthcare system. ${ }^{1}$ Intensive care unit (ICU) is special ward of hospital where patients are admitted due to suffering from chronic critical illnesses. ${ }^{2}$ Polypharmacy is common in patient admitted in ICU. ${ }^{2}$ Antimicrobials are the most frequently prescribed drugs in ICU for prophylaxis and management of infections. ${ }^{3}$ Due to wide spread use and inappropriate use of antimicrobials

\footnotetext{
*Address for correspondence:
}

Dr Prakash Rameshbhai Shelat, Assistant Professor, Department of Pharmacology, P.D.U. Govt. Medical College, E 28 Govt Medical Quarter, High rise tower, Jamnagar Road, Rajkot, India. E-mail: dr.prakashshelat@gmail.com 
developed multidrug resistant organisms and increase hospital acquired infections. ${ }^{4}$ It can lead to increased morbidity, mortality, length of hospital stay, and healthcare expenditures. ${ }^{5,6}$ Inappropriate use of broad spectrum antimicrobials lead to decreases sensitivity of antimicrobials against microorganisms. Increasing multidrug resistance with limited availability of newer agents there is urgent need for vigilant surveillance, stringent infection control practices, as well as rational anti-biotic prescription. ${ }^{7}$ Our hospital has anti-microbial policy which divide antimicrobials into restricted and unrestricted category. There is limited data from Indian ICUs as well as our hospital on drugs and antimicrobial utilization along with its sensitivity in the ICUs. Hence, we proposed to study the drug utilization pattern into the ICUs.

\section{MATERIAL AND METHODS}

Our study was prospective, continuous and observational conducted at tertiary care teaching hospital for a period of 23 months in 2009-2011. Approval from Medical Superintendent of institute and Institutional Ethical Committee (Ref No. EC/Approval/38/10) were taken before starting the study. Investigator visited each medical, surgical and neurosurgical ICU every day. 100 adult patients from each ICU who were prescribed antimicrobials were included in study after obtaining written informed consent. All information like age, gender, prescribed drugs and antimicrobials, report of culture sensitivity test etc. were collected and recorded preformed CRF. Antimicrobials and other drugs were classified using the ATC Classification System and drug utilization was measured as DDD/100 bed-days.

The DDD is the assumed average maintenance dose per day for a drug used for its main indication in adults.

The DDD per100 bed-days was calculated by the formula:

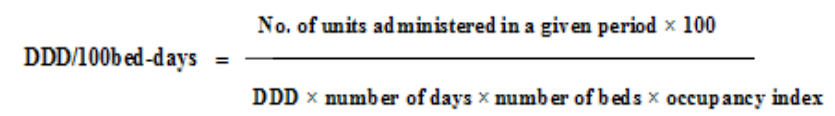

\section{Statistical Analysis}

All the data was entered into Microsoft Excel sheet and subjected to statistical analysis test. The data were analyzed by $\mathrm{Z}$ test and $\mathrm{x}^{2}$ test.

\section{RESULTS}

Analysis of demographic criteria

It was observed that $60 \%, 64 \%$ and $68 \%$ patients in age group of $40-60$ years and $58 \%, 61 \%$ and $64 \%$ patient were male in medical, surgical and neurosurgical ICU respectively. Mortality after 14 days of ICU was significantly $(p<0.05)$ higher in medical ICU as compared to surgical and neurosurgical ICU. Duration of stay in ICU was significantly $(\mathrm{p}<0.05)$ higher in medical and neurosurgical ICU as compared to surgical ICU. It was observed that 5 to 14 drugs were prescribed with mean of $13.48 \pm 1.64$, $11.52 \pm 1.32$ and $12.30 \pm 1.46$ in medical, surgical and neurosurgical ICU respectively. In medical ICU 46\%, surgical ICU $86 \%$ and neurosurgical ICU $77 \%$ patients were prescribed either 3 or 4 antimicrobials. There was statistically significance in prescribing antimicrobials by generic name as compared to brand name in all ICUs. Average duration of antimicrobial agent was significantly $(p<0.05)$ higher in neurosurgical and medical ICU as compared to surgical ICU (Table 1).

Analysis Daily Defined Dose (DDD) per 100 bed days of drugs DDD/100 bed days of inotropes (adrenaline, noradreanline, dopamine), anticholinergic drugs (atropine) cardiovascular drugs (aspirin, clopidogrel, digoxin, atorvastatin etc) and respiratory drugs (salbutamol, Etofylline+theophylline hydrate) were significantly $(\mathrm{p}<0.05)$ higher in medical ICU as compared to surgical and neurosurgical ICU. DDD/100 bed days of corticosteroids (beclomethasone, dexomethasone, drugs acting on central nervous system (phenytoin, sodium valproate, diazepam, lorazepam) and diuretics (furosemide) were significantly $(p<0.05)$ higher in neurosurgical ICU as compared to medical and surgical ICU. DDD/100 bed days of gastrointestinal drugs (ranitidine, pantoprazole, omeprazole, ondansetron) and analgesics (diclofenac, tramadol) were significantly $(\mathrm{p}<0.05)$ higher in surgical ICU and neurosurgical ICU as compared to medical ICU. DDD/100 bed days of antimicrobials was similar to all ICUs (Table $2 \mathrm{a}, \mathrm{b}$ ).

Analysis of DDD/100 bed days of antimicrobials group DDD/100 bed days of penicillin, aminoglycosides, nitroimidazole and macrolide were significantly $(\mathrm{p}<0.05)$ higher in surgical and neurosurgical ICU as compared to medical ICU. DDD/100 bed days of cephalosporin and fluroquinolone were significantly $(\mathrm{p}<0.05)$ higher in medical and neurosurgical ICU as compared to surgical ICU (Table 3).

DDD/100 bed days of antimicrobials according to antimicrobial policy of hospital

Among unrestricted antimicrobials of policy DDD/100 bed days of ceftriaxone, ciprofloxacin and ofloxacin were significantly $(p<0.05)$ higher in medical ICU as compared to surgical and neurosurgical ICU. DDD/100 bed days of amoxicillin-clavulanate, cefotaxime, amikacin and 


\begin{tabular}{|c|c|c|c|c|}
\hline \multicolumn{2}{|c|}{ ICU } & $\begin{array}{c}\text { MICU } \\
(n=100)\end{array}$ & $\begin{array}{c}\text { SICU } \\
(n=100)\end{array}$ & $\begin{array}{l}\text { NSICU } \\
(n=100)\end{array}$ \\
\hline \multirow{3}{*}{$\begin{array}{l}\text { Age group } \\
\text { (years) }\end{array}$} & $20-40$ & 24 & 22 & 15 \\
\hline & $40-60$ & 60 & 64 & 68 \\
\hline & More than 60 & 16 & 14 & 17 \\
\hline \multicolumn{2}{|c|}{ Male/ Female } & $58 / 42$ & $61 / 39$ & $64 / 36$ \\
\hline \multicolumn{2}{|c|}{ Mortality before 14 days } & 22 & 18 & 14 \\
\hline \multicolumn{2}{|c|}{ Mortality after 14 days } & $57^{*}$ & 21 & 19 \\
\hline \multicolumn{2}{|c|}{ Transfer to ward } & 16 & 54 & 59 \\
\hline \multicolumn{2}{|c|}{ Duration of stay in ICU } & $9.2 \pm 1.29^{\#}$ & $5.7 \pm 1.04$ & $11.2 \pm 1.16^{\#}$ \\
\hline \multicolumn{2}{|c|}{$\begin{array}{l}\text { Average no. of drugs } \\
\text { prescribed(Mean } \pm \text { SEM) }\end{array}$} & $13.48 \pm 1.64$ & $11.52 \pm 1.32$ & $12.30 \pm 1.46$ \\
\hline \multirow{3}{*}{$\begin{array}{c}\text { No of } \\
\text { antimicrobial } \\
\text { agents }\end{array}$} & 1 and 2 & 12 & 03 & 09 \\
\hline & 3 and 4 & 46 & 86 & 77 \\
\hline & More than 4 & 42 & 11 & 14 \\
\hline \multicolumn{2}{|c|}{$\begin{array}{l}\text { Average duration of } \\
\text { antimicrobial agents }\end{array}$} & $8.03 \pm 1.53^{\#}$ & $6.72 \pm 1.12$ & $10.8 \pm 1.31^{\#}$ \\
\hline \multicolumn{2}{|c|}{$\begin{array}{l}\text { Antimicrobials prescribed by } \\
\text { generic/brand name }\end{array}$} & $\begin{array}{l}273(66.26 \%)^{\star *} \\
/ 139(33.74 \%)\end{array}$ & $\begin{array}{l}232^{* *}(68.63 \%) \\
/ 106(31.37 \%)\end{array}$ & $\begin{array}{l}233(64.90 \%)^{\star *} \\
/ 126(35.10 \%)\end{array}$ \\
\hline
\end{tabular}

${ }^{*} \mathrm{p}<0.05$ (Ztest) significantly higher as compared to surgical and neurosurgical ICU; ${ }^{* *} \mathrm{p}<0.05\left(\mathrm{X}^{2}\right.$ test) significantly higher as compared to brand name in all ICU; $\#$ $<0.05$ (Ztest) significantly higher as compared to surgical ICU.

\begin{tabular}{|c|c|c|c|}
\hline Drugs & $\begin{array}{c}\text { Medical ICU } \\
\text { DDD/100 bed days }\end{array}$ & $\begin{array}{c}\text { Surgical ICU } \\
\text { DDD/100 bed days }\end{array}$ & $\begin{array}{l}\text { Neurosurgical ICU } \\
\text { DDD/100 bed days }\end{array}$ \\
\hline Inotropes & $51.54^{*}$ & 29.43 & 28.32 \\
\hline Anticholinergic & $35.33^{*}$ & 23.74 & 25.64 \\
\hline Gastrointestinal drugs & 14.13 & $44.52^{\star \star}$ & $38.17^{* *}$ \\
\hline Corticosteriods & 7.63 & 17.87 & $62.86^{\#}$ \\
\hline Analgesics & 13.76 & $34.5^{\star *}$ & $34.41^{\star *}$ \\
\hline CNS drugs & $15.43^{\# \#}$ & 8.32 & $28.53^{\#}$ \\
\hline Cardiovascular drugs & $13.54^{*}$ & 8.55 & 7.8 \\
\hline Diuretics & 5.24 & $11.21^{\star *}$ & $16.33^{\#}$ \\
\hline Respiratory drugs & $9.02^{*}$ & 5.33 & 7.21 \\
\hline Electrolytes & 4.24 & 4.07 & 3.91 \\
\hline Antimicrobial agents & 48.42 & 46.57 & 52.81 \\
\hline
\end{tabular}

metronidazole were significantly $(\mathrm{p}<0.05)$ higher in surgical and neurosurgical ICU as compared to medical ICU while DDD/100 bed days of ceftazidime was significantly $(p<0.05)$ higher in neurosurgical ICU as compared to medical and surgical ICU. Among restricted antimicrobials of policy DDD/100 bed days of piperacillin +tazobactam, cefoperazone+sulbactam were significantly $(\mathrm{p}<0.05)$ higher in medical ICU as compared to surgical ICU and neurosurgical ICU. DDD/100 bed days of vancomycin was significantly $(\mathrm{p}<0.05)$ higher in surgical ICU as compared to medical and neurosurgical ICU while DDD/100 bed days of linezolid was significantly $(\mathrm{p}<0.05)$ higher in neurosurgical ICU as compared to medical and surgical ICU (Table 4 a,b).
Sensitivity of most commonly prescribed antimicrobials

For culture sensitivity test 129 samples were collected from all ICUs. No micro-organisms found in 76 samples and sensitivity of antimicrobials was observed in remaining 53 samples. Sensitivity percentage to beta lactam antimicrobials with beta lactamase inhibitors was significantly $(\mathrm{p}<0.05)$ higher as compared beta lactam alone in all ICUs. Vancomycin and levofloxcin more than $80 \%$ sensitive in all ICUs which was significantly $(p<0.05)$ higher as compared to beta lactam anti-microbials with beta lactamase inhibitors. Sensitivity of linezolid was higher as compared to beta lactam antimicrobials but lower as compared to beta lactam anti-microbial with beta lactamase inhibitors (Figure 1). 
Table 2: b) Analysis of DDD per 100 bed days individual drugs

\begin{tabular}{|c|c|c|c|c|c|c|c|c|}
\hline \multirow[b]{2}{*}{ Drugs } & \multirow[b]{2}{*}{ ATC DOE } & \multirow{2}{*}{$\begin{array}{l}\text { DDD by } \\
\text { WHO }\end{array}$} & \multicolumn{2}{|c|}{ Medical ICU } & \multicolumn{2}{|c|}{ Surgical ICU } & \multicolumn{2}{|c|}{ Neurosurgical ICU } \\
\hline & & & $\begin{array}{c}\text { Units } \\
\text { prescribed }\end{array}$ & $\begin{array}{c}\text { DDD/100 bed } \\
\text { day }\end{array}$ & $\begin{array}{l}\text { Units } \\
\text { prescribed }\end{array}$ & $\begin{array}{c}\mathrm{DDD} / 100 \text { bed } \\
\text { days }\end{array}$ & $\begin{array}{l}\text { Units } \\
\text { prescribed }\end{array}$ & $\begin{array}{c}\text { DDD/100 bed } \\
\text { days }\end{array}$ \\
\hline Atropine & A03BA01 & $1.5 \mathrm{mg}$ & 1710 & $32.57^{*}$ & 788 & 22.51 & 864 & 24.51 \\
\hline Nor adrenaline & C01CA03 & $6 \mathrm{mg}$ & 464 & $2.14^{*}$ & 241 & 1.43 & 118 & 0.7 \\
\hline Adrenaline & C01CA24 & $0.5 \mathrm{mg}$ & 1674 & $39.85^{\star}$ & 892 & 21.23 & 734 & 21.84 \\
\hline Dopamine & $\mathrm{C} 01 \mathrm{CA} 04$ & $0.5 \mathrm{gm}$ & 1056 & $5.02^{*}$ & 424 & 3.02 & 367 & 2.62 \\
\hline Dobutamine & C01CA07 & $0.5 \mathrm{gm}$ & 745 & $4.43^{*}$ & 421 & 3.75 & 354 & 3.16 \\
\hline Beclomethasone & H07AC01 & $1.5 \mathrm{mg}$ & 37 & 1.17 & 12 & 0.57 & 298 & $14.19^{\#}$ \\
\hline Dexomethasone & H02АB02 & $1.5 \mathrm{mg}$ & 53 & 0.84 & 43 & 1.02 & 936 & $22.85^{\#}$ \\
\hline Hydrocortisone & Н02АВ09 & $30 \mathrm{mg}$ & 134 & 5.31 & 236 & 14.04 & 329 & $19.58^{\#}$ \\
\hline Salbutamol & R03AC02 & $0.8 \mathrm{mg}$ & 452 & $0.67^{*}$ & 132 & 0.29 & 159 & 0.35 \\
\hline $\begin{array}{l}\text { Etofylline+theophy } \\
\text { line hydrate }\end{array}$ & R03DA54 & $0.4 \mathrm{gm}$ & 408 & $8.01^{*}$ & 134 & 3.94 & 237 & $6.98^{\# \#}$ \\
\hline Aspirin & B01AC06 & $75 \mathrm{mg}$ & 184 & $2.19^{*}$ & 82 & 1.46 & 85 & 1.51 \\
\hline Atorvastatin & C10AA05 & $20 \mathrm{mg}$ & 192 & $2.28^{*}$ & 98 & 1.75 & 86 & 1.53 \\
\hline Clopidogrel & B01AC04 & $75 \mathrm{mg}$ & 183 & $2.17^{*}$ & 89 & 1.58 & 86 & 1.54 \\
\hline Amlodipine & C08CA01 & $5 \mathrm{mg}$ & 182 & $2.16^{*}$ & 45 & 0.8 & 56 & 1 \\
\hline Metoprolol & C07AB02 & $0.15 \mathrm{mg}$ & 195 & $0.77^{\star}$ & 36 & 0.21 & 33 & 0.19 \\
\hline Digoxin & C01AA05 & $0.25 \mathrm{mg}$ & 102 & $2.42^{*}$ & 24 & 0.85 & 14 & 0.5 \\
\hline Furosemide & С03CA01 & $40 \mathrm{mg}$ & 764 & 5.54 & 824 & 6.25 & 1146 & $12.38^{\# \#}$ \\
\hline Ranitidine & A02BA02 & $0.3 \mathrm{gm}$ & 2320 & 4.6 & 2870 & $8.54^{* *}$ & 2389 & $7.11^{\star *}$ \\
\hline Pantoprazole & А02BC02 & $40 \mathrm{mg}$ & 602 & 7.16 & 1056 & $18.85^{\star \star}$ & 982 & $17.53^{\star *}$ \\
\hline Ondansetron & A04AA01 & $16 \mathrm{mg}$ & 468 & 1.39 & 1656 & $7.39^{* *}$ & 1076 & $4.8^{\star \star}$ \\
\hline Omeprazole & А02BC01 & $20 \mathrm{mg}$ & 20 & 0.23 & 473 & $8.44^{* *}$ & 305 & $5.44^{\star *}$ \\
\hline Phenytoin & N03AB02 & $0.3 \mathrm{gm}$ & 898 & $3.56^{\# \#}$ & 364 & 2.16 & 1686 & $10.03^{\#}$ \\
\hline Sodium valproate & N03AG01 & $1.5 \mathrm{gm}$ & 1022 & $0.81^{\# \#}$ & 142 & 0.16 & 1287 & $1.53^{\#}$ \\
\hline Diazepam & N05BA01 & $10 \mathrm{mg}$ & 289 & $3.44^{\# \#}$ & 117 & 2.08 & 343 & $6.12^{\#}$ \\
\hline Lorazepam & N05BA06 & $2.5 \mathrm{mg}$ & 219 & $3.98^{\# \#}$ & 93 & 2.65 & 213 & $6.08^{\#}$ \\
\hline Midazolam & N05CD08 & $15 \mathrm{mg}$ & 764 & $3.03^{\# \#}$ & 214 & 1.27 & 802 & $4.77^{\# \#}$ \\
\hline Tramadol & N02AX02 & $0.3 \mathrm{gm}$ & 876 & 3.47 & 1022 & $6.08^{* *}$ & 1084 & $6.45^{\star *}$ \\
\hline Diclofenac & M01AB05 & $0.1 \mathrm{gm}$ & 1025 & 9.15 & 1685 & $22.56^{\star *}$ & 1588 & $21.26^{\star \star}$ \\
\hline Sodium chloride & $\mathrm{A} 12 \mathrm{CA} 01$ & $1 \mathrm{gm}$ & 252 & 1.35 & 130 & 1.04 & 63 & 0.5 \\
\hline $\begin{array}{l}\text { Magnisium } \\
\text { Sulphate }\end{array}$ & $\mathrm{A} 12 \mathrm{CC} 02$ & $1 \mathrm{gm}$ & 198 & 2.35 & 89 & 1.58 & 103 & 1.83 \\
\hline
\end{tabular}

${ }^{*} p<0.05$ (Ztest) significantly higher as compared to surgical and neurosurgical ICU; ** $p<0.05$ (Ztest) significantly higher as compared to medical ICU

$\# \mathrm{p}<0.05$ (Ztest) significantly higher as compared to medical and surgical ICU; $\#$ $<<0.05$ (Ztest) significantly higher as compared to surgical ICU

Table 3: Analysis of DDD per 100 bed days in antimicrobial groups

\begin{tabular}{|c|c|c|c|}
\hline Antimicrobial groups & MICU & SICU & NSICU \\
\hline & DDD/ 100 bed days & DDD/ 100 bed days & DDD/ 100 bed days \\
\hline Cephalosporin & $23.76^{\star \# \#}$ & 8.05 & $12.71^{\# \#}$ \\
\hline Penicillin & 6.1 & $7.51^{* \star}$ & $7.22^{* *}$ \\
\hline Fluroquinolones & $5.9^{\# \#}$ & 2.71 & $5.8^{\# \#}$ \\
\hline Aminoglycosides & 4.98 & $16.01^{\star *}$ & $17.65^{\star *}$ \\
\hline Nitroimidazole & 3.72 & $10.3^{\star *}$ & $8.04^{\star \star}$ \\
\hline Macrolides & 0.35 & $0.74^{* *}$ & $1.12^{* *}$ \\
\hline Monobactam & 0.06 & 0.23 & 0.17 \\
\hline Others & $3.55^{*}$ & 0.72 & 0.1 \\
\hline
\end{tabular}

${ }^{*} \mathrm{p}<0.05$ (Ztest) significantly higher as compared to surgical and neurosurgical ICU; ${ }^{* *} \mathrm{p}<0.05$ (Ztest) significantly higher as compared to medical ICU; ${ }^{\# \#} \mathrm{p}<0.05$ (Ztest) significantly higher as compared to surgical ICU. 
Table 4: a) DDD per 100 bed days in unrestricted antimicrobials according to antibiotic policy of hospital

\begin{tabular}{|c|c|c|c|c|c|c|c|c|}
\hline \multirow{2}{*}{$\begin{array}{c}\text { Name of } \\
\text { antimicrobial } \\
\text { agents }\end{array}$} & \multirow[b]{2}{*}{ ATC CODE } & \multirow[b]{2}{*}{$\begin{array}{c}\text { DDD by } \\
\text { WHO (gms) }\end{array}$} & \multicolumn{2}{|c|}{ Medical ICU } & \multicolumn{2}{|c|}{ Surgical ICU } & \multicolumn{2}{|c|}{ Neurosurgical ICU } \\
\hline & & & $\begin{array}{l}\text { Prescribed } \\
\text { dose in gms }\end{array}$ & $\begin{array}{c}\text { DDD/100 bed } \\
\text { days }\end{array}$ & $\begin{array}{l}\text { Prescribed } \\
\text { dose in gms }\end{array}$ & $\begin{array}{c}\text { DDD/100 bed } \\
\text { days }\end{array}$ & $\begin{array}{l}\text { Prescribed } \\
\text { dose in gms }\end{array}$ & $\begin{array}{l}\text { DDD/100 } \\
\text { bed days }\end{array}$ \\
\hline $\begin{array}{l}\text { Crystallne } \\
\text { penicillin }\end{array}$ & J01CE01 & 3.6 & 36 & 0.11 & 0 & 0 & 0 & 0 \\
\hline $\begin{array}{l}\text { Amoxicillin- } \\
\text { Clavulanate }\end{array}$ & J01CR02 & 3 & 956.4 & 3.79 & 1152 & $6.85^{\star \star}$ & 1072.8 & $6.38^{* *}$ \\
\hline Cefoperazone & J01DD62 & 4 & 0 & 0 & 0 & 0 & 78 & 0.34 \\
\hline Cefotaxime & J01DD01 & 4 & 316 & 0.94 & 438 & $1.95^{\star *}$ & 711 & $3.17^{\star *}$ \\
\hline Ceftriaxone & J01DD04 & 2 & 2096 & $15.47^{*}$ & 146 & 1.3 & 170 & 1.51 \\
\hline Cefatazidime & J01DD02 & 4 & 116 & 0.34 & 80 & 0.35 & 414 & $1.84^{\#}$ \\
\hline Cefixime & J01DD08 & 0.4 & 0 & 0 & 1.2 & 0.05 & 0.8 & 0.03 \\
\hline Ciprofloxacin & J01MA02 & 0.5 & 24.2 & $0.57^{*}$ & 1 & 0.03 & 0.2 & 0.01 \\
\hline Ofloxacin & J01MA01 & 0.4 & 10 & $0.29^{*}$ & 0.2 & 0.01 & 0.2 & 0.01 \\
\hline Levofloxacin & J01MA12 & 0.5 & 21.1 & $5.02^{\# \#}$ & 75 & 2.67 & 162 & $5.78^{\# \#}$ \\
\hline Gatifloxacin & J01MA16 & 0.4 & 0.8 & 0.02 & 0 & 0 & 0 & 0 \\
\hline Amikacin & J01GB06 & 1 & 418.5 & 4.98 & 897 & $16.01^{\star *}$ & 988.5 & $17.65^{\star \star}$ \\
\hline Azithromycin & J01FA10 & 0.5 & 16 & 0.64 & 3 & 0.1 & 0 & 0 \\
\hline Metronidazole & J01XD01 & 1.5 & 469 & 3.72 & 865.5 & $10.3^{\star \star}$ & 676 & $8.04^{\star *}$ \\
\hline
\end{tabular}

Table 4: b) DDD per 100 bed days in restricted antimicrobials according to antibiotic policy of hospital

\begin{tabular}{|ccccccccc}
$\begin{array}{c}\text { Name of } \\
\text { antimicrobial } \\
\text { agents }\end{array}$ & $\begin{array}{c}\text { ATC } \\
\text { CODE }\end{array}$ & $\begin{array}{c}\text { DDD by } \\
\text { WHO } \\
\text { (gms) }\end{array}$ & $\begin{array}{c}\text { Prescribed } \\
\text { dose in gms }\end{array}$ & $\begin{array}{c}\text { DDD/100 bed } \\
\text { days }\end{array}$ & $\begin{array}{c}\text { Medical ICU } \\
\text { Prescribed } \\
\text { dose in gms }\end{array}$ & $\begin{array}{c}\text { DDD/100 } \\
\text { bed days }\end{array}$ & $\begin{array}{c}\text { Neurosurgical ICU } \\
\text { Prescribed } \\
\text { dose in gms }\end{array}$ DDD/100 \\
bed days
\end{tabular}

${ }^{*} \mathrm{p}<0.05$ (Ztest) significantly higher as compared to surgical and neurosurgical ICU; ${ }^{* *} \mathrm{p}<0.05$ (Ztest) significantly higher as compared to medical ICU; $\# \mathrm{p}<0.05$ (Ztest) significantly higher as compared to medical and surgical ICU; \#\#p<0.05 (Z test) significantly higher as compared to surgical ICU; @ $p<0.05$ (Ztest) significantly higher as compared to medical and neurosurgical ICU.

\section{DISCUSSION}

\section{Analysis of demographic criteria}

In our study age group of 40-60 (years) was more than $60 \%$ patients in all ICUs which was higher to study at Kuwait where $45 \%$ patients in same group. ${ }^{8}$ More than $55 \%$ patients were male in all ICUs which was similar to study by Biswal et al. ${ }^{9}$ In contrast to our study, Smythe et al., reported equal number of male and female patients. ${ }^{10}$ In the Indian scenario it is noticed that female populations are reluctant to utilize health care faculties even if they are critically ill. ${ }^{2}$ Mortality after 14 days was significantly high in medical ICU (57\%) as compared to surgical (21\%) and neurosurgical (19\%) ICU that similar to study by Blot et al., where $61 \%$ death occurred after 14 days. ${ }^{11}$ Average duration of stay was more than 9 days in medical and neurosurgical ICU significantly higher compared to surgical ICU. Study from Bangalore reported that an average length of stay in ICU of 6 days which was lower as compared to our study. ${ }^{12}$
Majority patients in medical ICU were on ventilator support and mortality as well as length of stay was observed higher in patients on ventilator. In neurosurgical ICU patients were admitted for post operative care. Average more than 11 drugs was prescribed in all ICUs which was similar to study by Smythe et al., where mean number of drugs was $12.6 \pm 7.6 .^{9}$ Polypharmacy was common in ICU due to critical and comorbid illness. In all ICUs above $75 \%$ patients were prescribed more than 2 antimicrobials which was contrast to study conducted at Puducherry where only $17 \%$ patients were given a more than 2 antimicrobials. ${ }^{12}$ Prescribing more than two antimicrobials may be due to critical illness and longer duration of stay. In all ICUs more than $60 \%$ antimicrobials prescribed by generic name as compared to brand name while study conducted at South India reported that $29.20 \%$ antimicrobials were prescribed in generic names. ${ }^{12}$ Antimicrobials were supplied from state government and drugs were prescribed by brand name in unavoidable circumstance in our study. Average duration 


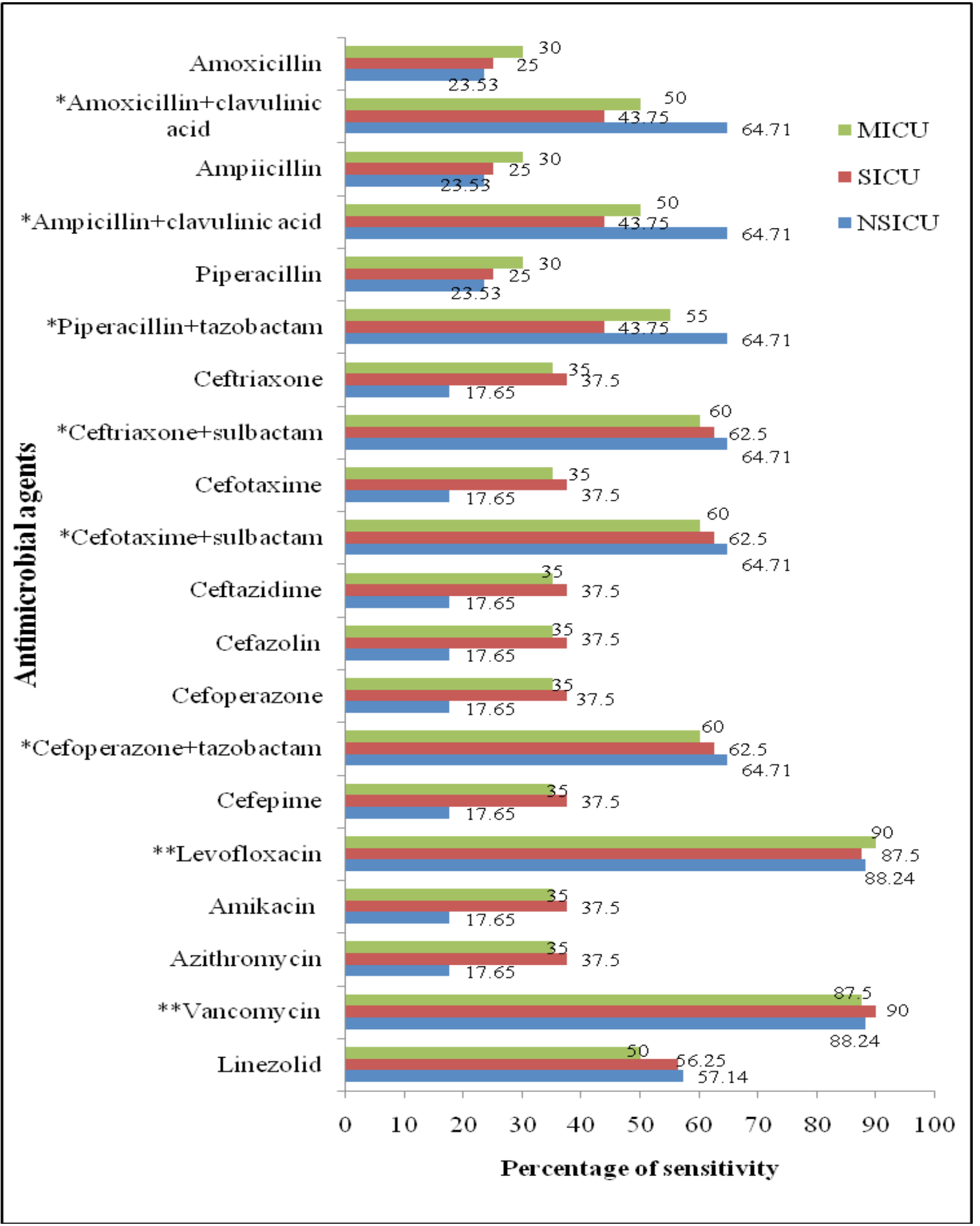

Figure 1: Senstivity of antimicrobial agents in medical, surgial and neurosurgical ICU $(n=53)$ ${ }^{*} \mathrm{p}<0.05$ (Ztest) significantly higher as compared to betalactam antimicrobials; ${ }^{* *} \mathrm{p}<0.05$ (Ztest) significantly higher as compared to others antimicrobials. 
of antimicrobial agent was more than 8 days significantly higher in neurosurgical and medical ICU while it was 6 days in study conducted at Manglore. ${ }^{4}$ Patients of critical illness required longer duration of antimicrobial therapy.

Analysis Daily Defined Dose (DDD) per 100 bed days of drugs Among anti-cholinergic drugs DDD/100 bed days of atropine was significantly $(p<0.05)$ higher in medical ICU. Atropine was prescribed in patients of organophosphate poisoning, and to decrease heart rate in critically ill patients. In inotropes, DDD/100 bed days of adrenaline, noradreanline, dopamine was significantly $(\mathrm{p}<0.05)$ higher in medical ICU. Adrenaline was mainly used for cardiac resuscitation and cardio respiratory arrest. Dopamine, dobutamine and noradrenaline were used to restore cardiac output, tissue perfusion and oxygenation. ${ }^{13}$ Among cardiovascular drugs DDD/100 bed days of aspirin, clopidogrel, digoxin, atorvastatin etc. were significantly $(\mathrm{p}<0.05)$ higher in medical ICU which was similar to studies reported by Smythe et al., and Biswal et al. ${ }^{9,10}$ In respiratory drugs DDD/100 bed days of salbutamol, etofylline+ theophylline hydrate was significantly $(\mathrm{p}<0.05)$ higher in medical ICU. Salbutamol and theophylline were prescribed in case of respiratory failure or difficulty in breathing which was more observed in medical ICU and similar report observed by Shankar et al. ${ }^{3}$ In corticosteroids, $\mathrm{DDD} / 100$ bed days of beclomethasone, dexomethasone were significantly $(p<0.05)$ higher in neurosurgical ICU. Corticorticoids have proven to be beneficial in controlling tumor-associated pain and limiting nausea and vomiting in operated neurosurgical patients. ${ }^{14} \mathrm{DDD} / 100$ bed days of phenytoin, sodium valproate, diazepam, lorazepam were significantly $(\mathrm{p}<0.05)$ higher in neurosurgical ICU as anticonvulsant and sedatives were prescribed neurosurgical patients to prevent and management of convulsive episodes. DDD/100 bed days of furosemide was also significantly $(p<0.05)$ higher in neurosurgical ICU. Furosemide was required to maintain body fluid level which was more concerned in neurosurgical patients. DDD per 100 bed days of proton pump inhibitors and analgesics like diclofenac, tramadol were significantly $(p<0.05)$ higher in surgical ICU and neurosurgical ICU. Proton pump inhibitors can prescribed for prophylaxis and management of stress induced and drug induced ulcers among critically ill patients. ${ }^{12}$ Analgesics were commonly prescribed in both surgical and neurosurgical ICU for management of postoperative pain.

Analysis of DDD of antimicrobials group

Total antimicrobial usage DDD/100 bed day was 44.42 , 46.27 and 52.81 in medical, surgical and neurosurgical ICU respectively which was lower as compared to study carried out at Germany where the total antibiotic usage DDD/100 bed day was 133.7. Germany study was carried out in 35 ICUs while our study was carried out in three ICUs. ${ }^{15} \mathrm{DDD} / 100$ bed days of penicillin, aminoglycosides and nitroimidazole were significantly $(p<0.05)$ higher in surgical (7.51, 16.01 and 10.3) and neurosurgical (7.22, 17.65 and 8.4) ICU as compared to medical ICU (6.1, 4.98 and 3.72) respectively. Shankar et al., reported that utilization of penicillin was $55.1 \mathrm{DDD} / 100$ bed days which was higher as compared to our study. ${ }^{3}$ Study conducted at Czech Republic reported that DDD/100 bed days of aminoglycosides was 8.79 which was lower as compared to surgical and neurosurgical ICU. ${ }^{16}$ Biswal et al., documented metronidazole as the commonly prescribed antimicrobial agent in their study. ${ }^{9}$ Variation was observed in antimicrobials prescribed in different region and ICU in the world may be due to sensitivity pattern of antimicrobials.

DDD/100 bed days of antimicrobials according to antimicrobial policy of hospital

DDD/100 bed days of amoxicillin-clavulanate, amikacin and metronidazole were significantly $(\mathrm{p}<0.05)$ higher in surgical $(6.85,16.01,10.03)$ and neurosurgical ICU $(6.38$, 17.65 and 8.04). Santosh EF et al., reported that DDD/100 bed days ampicillin+sulbactam was $41.74 .{ }^{17}$ Wiliams et al., reported that DDD/100 bed days of amikacin and metronidazole were 8.15 and 14.65 respectively which was higher compared to our study. ${ }^{5}$ Due to amoxicillinclavulanate as broad spectrum anti-microbial, amikacin effective against abdominal enterobacteria and metronidazole effective against anaerobe they were prescribed significantly in surgical and neurosurgical ICU to prevent post operative infections.

DDD/100 bed days of cephalosporin and fluroquinolone were significantly $(p<0.05)$ higher in medical $(20.76$ and 5.9) and neurosurgical ICU (12.71 and 5.8) as compared to surgical ICU (8.05 and 2.71) respectively. Shankar et al., reported that the utilization of cephalosporins and fluroquinolones, were 13.74 and $5.34 \mathrm{DDD} / 100$ bed-days respectively which was similar to our report. ${ }^{3} \mathrm{DDD} / 100$ bed days of ceftriaxone was significantly $(\mathrm{p}<0.05)$ higher in medical ICU (15.47) and DDD/100 bed days of cefotaxime was significantly $(\mathrm{p}<0.05)$ higher in surgical (1.95) and neurosurgical ICU(3.17) while DDD/100 bed days of ceftazidime was significantly $(\mathrm{p}<0.05)$ higher in neurosurgical ICU(1.84). Patel et al., reported that DDD/100 bed days of ceftrixone and cefotaxime were 7.41 and 5.53 respectively which was higher compared to our study. ${ }^{18}$ Vojtova V et al., reported that DDD/100 bed days of ceftazidime was 2.19 which was higher as compared 
to our study. ${ }^{16}$ Ceftriaxone, cefotaxime and ceftazidime were prescribed as empirical therapy due to their broad spectrum in our study. DDD/100 bed days of levofloxacin was significantly $(p<0.05)$ higher in medical ICU (5.02) and neurosurgical ICU (5.78). Williams et al., reported that DDD/100 bed days of levofloxacin was 15.97 which was higher as compared to our study. ${ }^{5}$ Levofloxacin was most commonly prescribed for the treatment and prevention of hospital acquired pneumonia in medical and neurosurgical ICUs.

Among the restricted antimicrobials DDD/100 bed days of piperacillin+tazobactam (2.2), cefoperazone+sulbactam (7.01) were significantly $(\mathrm{p}<0.05)$ higher in medical ICU. Vojtova $\mathrm{V}$ et al., reported that DDD/100 bed days of piperacillin+tazobactam and cefoperazone + sulbactam was 3.17 and 0.21 which was higher and lower compared to our study respectively. ${ }^{16}$ Sensitivity of cefoperazone+ sulbactam and piperacillin+tazobactam were high at our set up. DDD/100 bed days of vancomycin was higher in surgical ICU (0.48) while study carried out at Brazil reported that DDD/100 bed days of vancomycin was 13.13 which was higher compared to our study. ${ }^{17}$ Vancomycin was prescribed against methicillin resistant Staphylococcus aureus which was observed in more in surgical ICU. DDD/100 bed days of linezolid was one (1) in neurosurgical ICU. Garcia MS et al., reported that linezolid use decreased from 202 to $25 \mathrm{DDD} / 100$ bed days still it was higher as compared to our study. ${ }^{19}$ In their study resistant to lizezolid against Staphylococcus aureus was observed while in our study linezolid was sensitive against Staphylococcus aureus.

Sensitivity of most commonly prescribed antimicrobials

Sensitivity percentage of amoxicillin+clavulinic acid, ampicillin+clavulinic acid, piperacillin +tazobactam (55, 43.75 and 64.71) was significantly higher as compared to sensitivity percentage of amoxicillin, ampicillin and pipracillin $(30,25$ and 23.53) in medical, surgical and neurosurgical ICU respectively. Jones ME, et al., reported that sensitivity of ampicilin was 6.7 and 12.6 in USA and Canada respectively which was lower compared to our study. ${ }^{20}$ Shakibaie MR et al., reported that all strain were fully resistant to piperacillin, while $6.7 \%$ strain was sensitive to piperacillin + tazobactam which was lower as compared to our study. ${ }^{21}$ Sensitivity percentage to cefotaxime + sulbactam, ceftriaxone + sulbactam and cefoperazone + sulbactam $(60$, 62.5 and 64.71) was significantly higher as compared to sensitivity percentage cefotaxime, ceftriaxone and cefoperazone $(35,37.5$ and 17.65) in medical, surgical and neurosurgical ICU respectively. Neil et al., reported that $20 \%$ strain was sensitive to the third-generation cephalosporins which was lower as compared to our study. ${ }^{22}$ Beta lactam along with in combinations with beta lactamase inhibitors were prescribed highly as compared to beta lactam alone at our set up.

Sensitivity percentage of vancomycin and levofloxacin were more than $80 \%$ in all ICUs. Study by Thati et al., reported that $93.57 \%$ strain was sensitive for vancomycin similar to our study while study carried out at Turkey reported that sensitivity percentage of levofloxaicn was 60-75 which was lower as compared to our study. ${ }^{23,24}$ Vancomycin was prescribed when infection occurred due to methicillin resistant Staphylococcus aureus while levofloxacin was prescribed in the patients when penicillin and cephalosporins with beta lactamase inhibitiors were resistant.

Sensitivity percentage of linezolid was more than $50 \%$ in all ICUs. Zhanel GG et al., reported that sensitivity rate of linezolid was above $90 \%$ which was higher as compared to our study. ${ }^{25}$ In neurosurgical ICU linezolid was prescribed due to its high sensitivity and reduce intracranial tension in post operative neurosurgical patients.

In our study, inotropes and cardiovascular drugs prescribed higher in medical ICU while gastrointestinal drugs and analgesics were prescribed higher in surgical and neurosurgical ICU. Corticosteroids and antiepileptic drugs were prescribed higher in neurosurgical ICU. Antimicrobials were prescribed most commonly and more than 2 antimicrobials prescribed in majority of the patient in all ICUs. Although antimicrobial policy of our hospital is available but some of the restricted antimicrobials are used in all ICUs. Hence we recommended following suggestion to improve rational use of antimicrobial agents:

- Education of prescriber by encourage to attend seminar, medical workshop, conference etc.

- Availability of antimicrobial policy in each ward, ICU and to prescriber

- Strict evaluation of implementation of antimicrobial policy

In our study limitation we did not study those patient who were shift from ward to ICU for critical care management and pregnant women as well as children.

\section{CONCLUSION}

In conclusion, our study reveals that antimicrobials are widely prescribed in critically ill patients and form a significant proportion of the total drugs consumed in the ICU. This study will helpful for education to prescribers, rational prescription of antimicrobials and better management of patients.

Journal of Young Pharmacists Vol $7 \bullet$ Issue $4 \bullet$ Oct-Dec 2015 


\section{ABBREVIATION}

ATC: Anatomical Therapeutic Chemical

CRF: Case Record Form

DDD: Daily Defined Dose
ICU: Intensive Care Unit

NSICU: Neurosurgical ICU

MICU: Medical ICU

SICU: Surgical ICU

\section{Highlights of Paper}

- DDD/100 bed days of inotropes was higher in medical ICU while DDD/100 bed days of gastrointestinal drugs and analgesics were higher in surgical and neurosurgical ICU.

- DDD/100 bed days of cephalosporins was higher in medical ICU while DDD/100 bed days of aminoglycosides and nitroimidazole were higher in surgical and neurosurgical ICU.

- Among restricted antimicrobials according to antimicrobial policy of hospital DDD/100 bed days of piperacilli+tazobacatm and cefoperazon+sulbactam were higher in medical ICU.

- Levoflxoacin and vancomycin were highly sensitive antimicrobials followed by beta lactam antimicrobials with beta lactamase inhibitors in all ICUs.

\section{Author Profile}

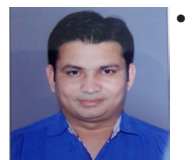

- Dr. Prakash Rameshbhai Shelat : Is an Assistant Professor at the Department of Pharmacology, P.D.U. Govt. Medical College, Rajkot. His interest is in the area of drug utilization studies, clinical trials and clinical research. He is also done many research paper and presentations.

\section{REFERENCES}

1. World Health Organization (WHO). Introduction to drug utilization research/WHO International Working Group for Drug Statistics Methodology, WHO Collaborating centre for Drug statistics Methodology, WHO collaborating centre for Drug Utilization Research and Clinical Pharmacological services. Geneva: WHO press, World Health Organization; 2003.

2. John LJ, Devi P John P, Guido S. Drug utilization study of antimicrobial agents in medical intensive care unit. Asian J Pharm Clin Res. 2011; 4(2): 81-4

3. Shankar PR, Partha P, Dubey AK, et al. Intensive care unit drug utilization in a teaching hospital in Nepal. Kathmandu Univ Med J. 2005 ; 3(10): 130-7.

4. Shrikala B, Kranti KR, Nafisa. A prospective study on evaluation of antibiotic prescription practices in an intensive care unit of a tertiary care hospital. Journal of Clinical and Diagnostic Research. December 2010; 4(6): 3387-91.

5. Williams A, Mathai AS, Phillips AS. Antibiotic prescription patterns at admission into tertiary level intensive care unit in Northern India. J pharm Bioall Sci. 2011; 3(1): 531-6.

6. Akilandeswari K, Ruckmani K. Studies on anti microbial potential of non-antibiotics on resistant bacteria - A Review. J Young Pharm. 2015; 7(2): 63-8.

7. Lockhart SR, Abramson MA, Beekman SE, Gallagher G, Riedel $\mathrm{SR}$, Diekma DJ, et al. Antimicrobial resistance among gramnegative bacilli as causes of infections in intensive care unit patients in the United States between 1993 and 2004. J Clin Microbiol. 2007; 45(10): 3352-9.

8. Aly NY, Al-Mousa HH, Aliasar SM. Nosocomial Infections in a medical-surgical Intensive Care Unit. Med Princ Pract. 2008; 17(5): 373-7.

9. Biswal S, Mishra P, Malhotra S, et al. Drug utilization pattern in the intensive care unit of a tertiary care hospital. J Clin Pharmacol. 2006; 46(8): 945-51.

10. Smythe MA, Melendy S, Jahns B, Dmuchowski C. An exploratory analysis of medication utilization in a medical intensive care unit. Crit Care Med. 1993; 21(9): 1319-23.

11. Blot S, Vandewoude K, Bacquer D, Colardyn F. Nosocomial Bacteremia Caused by Antibiotic-Resistant Gram-Negative
Bacteria in Critically III Patients: Clinical Outcome and Length of Hospitalization. Clin Infect Dis. 2002; 34(12): 1600-6.

12. Pandiamunian J, Somasundaram G. A study on prescribing pattern of anti microbial agents in the medical intensive care unit of a tertiary care teaching hospital in Puducherry union territory, South India. Int J Pharm Pharm. 2014; 6(3): 235-8.

13. Bangash MN, Kong ML, Pearse RM. Use of inotropes and vasopressor agents in critically ill patients. $\mathrm{Br} \mathrm{J}$ Pharmacol. 2012; 165(7): 2015-33

14. Ryken TC, McDermott M, Robinson PD, et al. The role of steroids in the management of brain metastases: a systematic review and evidence-based clinical practice guideline. J Neurooncol. 2010; 96(1): 103-11.

15. Meyer E, Jonas D, Schwab F, Rueden H, Gastmeier P, Daschner FD. Design of a surveillance system of antibiotic use and bacterial resistance in German intensive care units. Infection 2003; 31(4): 208-15.

16. Vojtova V, Kolar M, Hricova K, Uvizl R, Neiser J, Blahut L, et al Antibiotic utilization and Pseudomonas aeruginosa resistance in intensive care units. New Microbiologica. 2011; 34(3): 291-8.

17. Santosh EF, Lauria-pires L, Pereira MG, Silva AE. Use of Antibacterial Agents in an Intensive Care Unit in a Hospital in Brazil. Braz J Infect Dis. 2007; 11(3): 355-9.

18. Patel MK, Barvaliya MJ, Patel TK, Tripathi CB. Drug utilization pattern in critical care unit in a tertiary care teaching hospital in India. Int J Crit IIIn Inj Sci. 2013; 3(4): 250-5.

19. Garcıa MS, Dela Torre MA, et al. Clinical Outbreak of LinezolidResistant Staphylococcus aureus in an Intensive Care Unit. JAMA 2010; 303(22): 2260-4

20. Jones ME, Draghi DC, Thornsberry C, Karlowsky JA, Sahm DF, Wenzel RP. Emerging resistance among bacterial pathogens in the intensive care unit - a European and North American Surveillance study (2000-2002). Ann Clin Microbiol Antimicrob. 2004; 3(1): 14.

21. Shakibaie MR, Saied AS, Salehi MS. Antibiotic resistance patterns and extended spectrum b-lactamase production among Acinetobacter spp. isolated from an intensive care Unit of a hospital in Kerman, Iran. Antimicrob Resist Infect Control. 2012; 1(1): 1 . 
22. Neill EO, Humphreys H, Phillips J, Smyth EG. Third-generation cephalosporin resistance among Gram-negative bacilli causing meningitis in neurosurgical patients: significant challenges in ensuring effective antibiotic therapy. J Antimicrob Chemother. 2006; 57(2): 356-9.

23. Thati V, Shivannavar CT, Gaddad SM. Vancomycin resistance among methicillin resistant Staphylococcus aureus isolates from intensive care units of tertiary care hospitals in Hyderabad. Indian
J Med Res. 2011 November; 134(5): 704-8.

24. Namiduru M, Gungor G, Karaoglan I, Dikensoy O. Antibiotic Resistance of Bacterial Ventilator-associated Pneumonia in Surgical Intensive Care Units. J Int Med Res. 2004; 32(1): 78-83.

25. Zhanel GG, DeCorby M, et al. Antimicrobial-Resistant Pathogens in Intensive Care Units in Canada: Results of the Canadian National Intensive Care Unit (CAN-ICU) Study, 2005-2006. Antimicrob Agents Chemother. 2008 Apr; 52(4): 1430-7. 